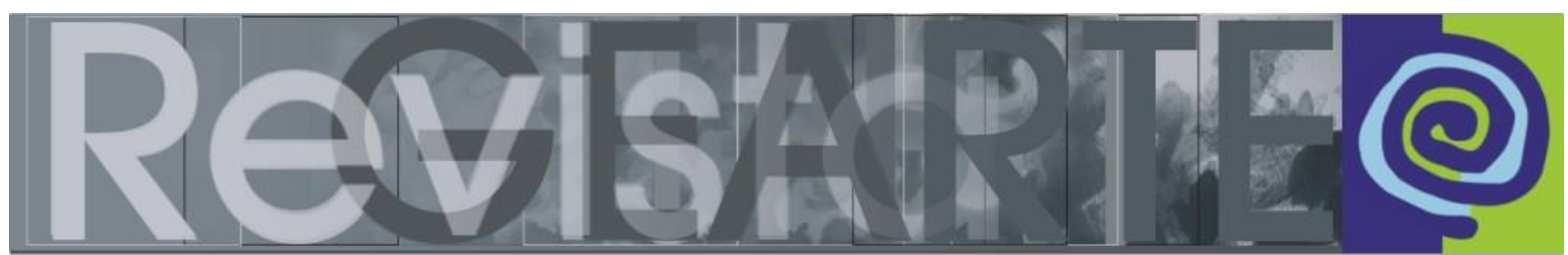

e-ISSN 2357-9854

\title{
Design Reverso: uma nova abordagem para análise e desenvolvimento de artefatos
}

\author{
João Carlos Vela (Universidade da Região de Joinville — UNIVILLE, \\ Joinville/SC, Brasil)
}

Ricardo Triska (Universidade Federal de Santa — UFSC, Florianópolis/SC, Brasil)

Beatriz Andrielly de Souza Nascimento (Universidade da Região de Joinville UNIVILLE, Joinville/SC, Brasil)

RESUMO - Design Reverso: uma nova abordagem para análise e desenvolvimento de artefatos - Este artigo possui como objetivo apresentar o Design Reverso, que consiste em uma nova abordagem de desenvolvimento de produtos, e para tal realizou-se uma análise das metodologias de design de 1920 até os dias atuais, com o propósito de demonstrar que estas mantêm uma estrutura semelhante e linear de desenvolvimento de produtos. Já o Design Reverso tem como premissa, de forma diferenciada das metodologias vigentes de design, partir de um artefato já existente para chegar a uma nova solução, sendo composta por duas etapas de análise: generalista e estruturada. Essa abordagem ainda se encontra em fase de desenvolvimento e, por isso, este artigo não apresenta resultados conclusivos. O Design Reverso não possui a pretensão de ser uma nova metodologia, mas sim uma ferramenta de apoio, que pode contribuir ou complementar as metodologias vigentes, colaborando principalmente com os docentes e acadêmicos de design, uma vez que possibilitará uma nova forma de desenvolvimento de produtos.

PALAVRAS-CHAVE

Design. Design Reverso. Metodologia e desenvolvimento de artefatos.

ABSTRACT - Reverse Design: a new approach to analyzing and developing artifacts - This article aims to present the Reverse Design, which consists of a new approach to product development and for this was carried out an analysis of design methodologies from 1920 to the present day, with the purpose of demonstrating that they maintain a similar structure and linear product development. On the other hand, the Reverse Design has as a premise and in a different way from the current design methodologies, from an existing artifact to arrive at a new solution, being composed of two stages of analysis: general and structured. This approach is still under development, and for this reason, this article does not present conclusive results. Reverse Design does not pretend to be a new methodology, but rather a support tool that can contribute or complement current methodologies, collaborating mainly with teachers and design scholars, as it will allow a new way of product development.

KEYWORDS

Design. Reverse Design. Methodology and development of artifacts.

\section{Introdução}

A prática de projeto em design desde seus primórdios até a contemporaneidade, tem por premissa partir do problema para resultar na solução, 
como pode-se verificar nos preceitos da Bauhaus e da Escola de Design de UIm, entre 1920-1950, bem como, nas metodologias desenvolvidas por diferentes autores, tais como: Alexander (1960), Lobach (1970), Munari (1980/2011), Gero (1990), Brown (séc. XXI), entre outros.

$\mathrm{Na}$ Academia isso se comprova, uma vez que a prática de ensino empregada na formação dos novos profissionais de Design está alinhada às metodologias vigentes, tais como as dos autores citados. Como consequência, estes profissionais quando estiverem no mercado de trabalho, irão aplicar esta forma linear de desenvolvimento de artefatos.

As metodologias de Design servem como base nos processos de criação, sendo necessário que os designers possuam uma boa compreensão e domínio dos métodos. Sendo assim, estudar as metodologias existentes, melhorar pontos de deficiência e inovar em métodos é importante no desenvolvimento de projetos. Para Bürdek (2006), o Design se tornou relativamente ensinável e aprendível e em função da discussão com a metodologia passou a ser comunicável. Afirma ainda que o aprendizado lógico e sistemático possui relação direta com a relevância da metodologia do Design para o ensino.

\section{Metodologias de Design}

O Design moderno teve seu início em meados do século XIX, com a Revolução Industrial, entretanto somente muitos anos depois, este se tornou algo ensinável. Vários processos foram criados e por consequência diferentes metodologias foram desenvolvidas. Bürdek (2006) aponta que as metodologias de Design tiveram início na década de 1960 com Christopher Alexander, considerado pelo autor um dos pais da metodologia, porém, não podemos desconsiderar a importância que as duas clássicas escolas de Design (Bauhaus e Ulm) tiveram na formação de novos profissionais. Portanto, este capitulo possui como premissa apresentar um panorama que compreende o espaço de tempo entre os anos de 1920 até os dias atuais. 


\section{De 1920 a 1950 - a essência do Design}

Ao falar de Design e das características que este foi assumindo ao longo do tempo, é indispensável discorrer sobre as duas precursoras e influentes escolas de Design do séc. XX: Bauhaus e a Escola Superior de Design de Ulm - a HFG. Essas escolas tiveram grande influência na consolidação do Design mundial e, de certa forma, caracterizam a essência do Design.

A Bauhaus foi uma escola de artes aplicadas e arquitetura que tinha o objetivo de formar profissionais capazes de aliar arte e técnica na produção de artefatos. Segundo Martins e Van Der Linden (2012, p. 33) "as raízes da pesquisa no Design nos anos 1920 encontram-se na Bauhaus, onde foram estabelecidas muitas bases metodológicas para o ensino do Design".

Gropius (2004) ressalta que na concepção da Bauhaus, o aprender estava diretamente ligado ao fazer, havendo então a ligação entre o aprendizado e o fazer artístico, ou seja, reintegrando arte e ofícios. Para o autor era fundamental que o profissional tivesse competências para proceder com a passagem do artesanato para a indústria, utilizando os meios de produção industrial para inserir a arte no cotidiano.

A Bauhaus tornou-se sinônimo de pensamento avançado em Design e muitas vezes o movimento é reconhecido como um estilo, o que nunca foi pretendido pelos seus membros. Seus estudos e experimentos impulsionaram a visão que se tem hoje, principalmente quando se refere à linguagem visual e ao ensino básico dos acadêmicos. Entretanto, Martins e Van Der Linden (2012) afirmam que os métodos adotados pela instituição eram insuficientes, uma vez, que em grande parte, eram intuitivos e não abordavam a problematização do Design como um todo. Apesar das limitações, esses métodos dominaram o campo do Design e muitos designers relevantes tiveram esses como referências.

Já a história da Escola de Ulm teve início com Max Bill quando a fundou com a proposta de continuar o legado da Bauhaus. Bürdek (2006) afirma que a Escola de Ulm influenciou a teoria, a prática, o ensino do Design e a comunicação visual, assim como a Bauhaus nos anos 1920 influenciou a arquitetura, a configuração e a arte. 
Desta forma, a comparação entre essas duas instituições torna-se legítima. O autor aponta também que inicialmente eram ex-bauhausianos que ministravam as aulas na Escola.

A Escola de Ulm tinha como característica um ensino estritamente tecnológico e científico, distanciando-se do caráter intuitivo herdado da Bauhaus. Esta ruptura criou a necessidade de uma nova orientação estética. Com isto, a estética passou a seguir a função e o Design começou a ser visto pela escola numa perspectiva mais industrial. Esses fatos colaboraram para o "estilo UIm", caracterizado por um Design sem metáforas, frio, asséptico e objetivo, em que os produtos tinham uma aparência mais limpa e uma estética racional. (NIEMEYER, 2000; VELA, 2010)

A prática de ensino da Escola passou a ser altamente formalizada. Com isto, foi modelo de referência de outras escolas pelo mundo. Esta busca da Escola de Ulm por racionalidade e funcionalidade a aproximou do setor produtivo, no qual a instituição desenvolveu vários projetos em parceria com a indústria. (BURDEK, 2006; VELA, 2010)

Estas duas escolas foram um referencial até a década de 1960, uma vez que exerceram muitas influências conceituais e pedagógicas, contribuindo para 0 desenvolvimento do Design e para a formação acadêmica. A Bauhaus e a Escola de Ulm acabaram ficando conhecidas como estilos de Design, representando, cada uma em sua época de atuação e até mesmo atualmente, um ícone do Design.

A capacidade da Bauhaus de unir arte e oficio e da Escola de Ulm de unir estética e forma, estavam relacionadas diretamente com a melhoria dos processos na produção industrial. Entendemos que a relação dessas uniões: estética e fazer, função e racionalidade - como pode-se verificar na esquematização a seguir - caracteriza a essência do Design moderno, que consiste em três pilares: estética, função e produção. 


\section{Figura 1 - Essência do Design}

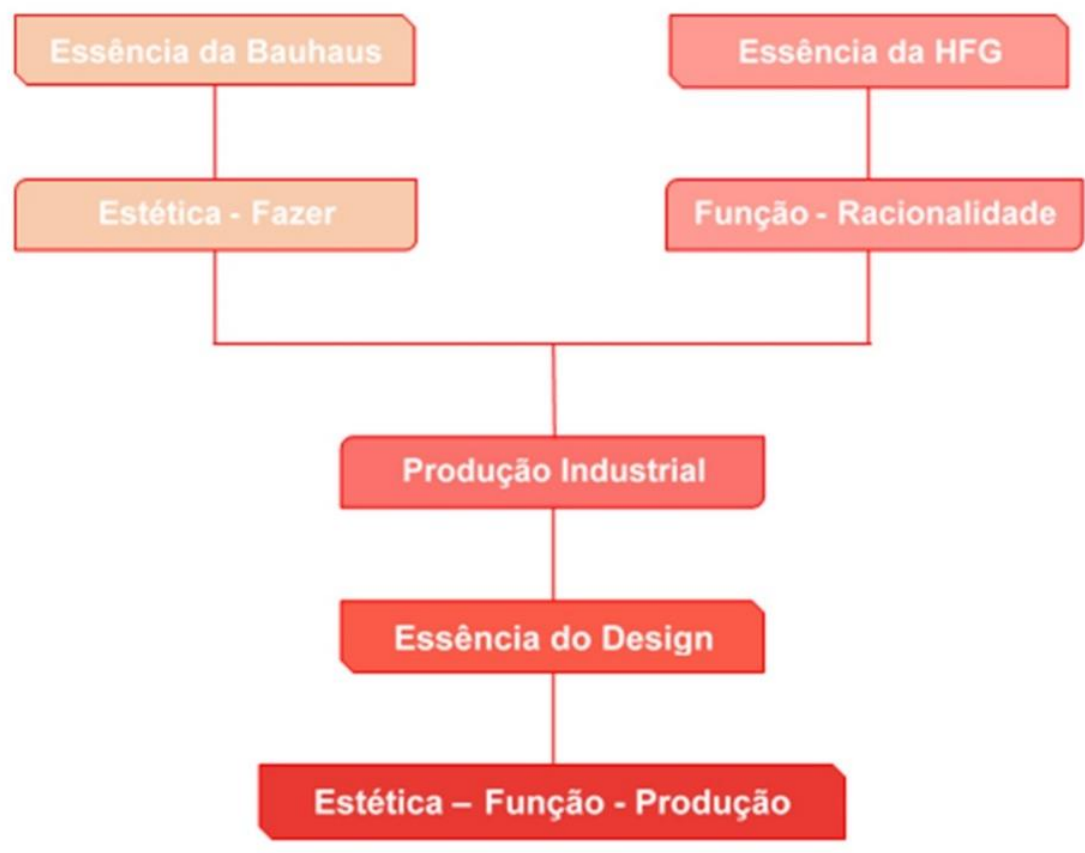

Fonte: Elaboração dos autores (2017).

Com o passar das décadas, as metodologias que foram surgindo, embora possuam algumas diferenças ou evoluções - na sua estrutura ou nos processos de Design - trazem no seu escopo, não só a influência das escolas de Bauhaus e Escola de Ulm, mas também o que entendemos ser a essência do Design moderno, como pode-se verificar a seguir nas metodologias dos autores elencados.

\section{As metodologias ao longo das décadas}

Os métodos utilizados até a década de 1960 eram, em grande parte, intuitivos e não contemplavam a problemática do Design como um todo. Bürdek (2006, p. 251) aponta que "os inícios da Metodologia do Design têm origem nos anos 1960, especialmente na Escola de Ulm, que se dedicava a este tema com intensidade. A motivação para isto era o aumento das tarefas dadas aos designers da indústria nesta época".

Neste contexto, é relevante o levantamento das características que as metodologias foram adquirindo ao longo das décadas, assim como a exemplificação das etapas pelas quais os autores estruturavam suas metodologias, com o intuito de 
demostrar como a diferenciação de nomenclaturas e de quantidade de etapas não interferem no esquema linear que seguem, possuindo a mesma estrutura.

As retomadas de metodologias têm como objetivo demonstrar que, independentemente de serem clássicas ou contemporâneas, seguem o mesmo raciocínio linear e a escolha dos autores para contextualizar cada década foi feita com base em livros, dissertações e teses que debatem sobre a metodologia de Design, tais como Bürdek (2006) e Vasconcelos (2009).

Os principais autores definidos de cada período foram:

- Década de 1960: Morris Asimow; Mihajlo D. Mesarovic; Leonard Bruce Archer e Christopher Alexander.

- Década de 1970: Thomas A. Marcus e Thomas W. Maver; John Chris Jones; Bernhard E. Bürdek; John Chris Jones; Bernd Löbach.

- Década de 1980: Bryan Lawson; Gui Bonsiepe; Verein Deutscher Ingenieure (VDI); Bruno Munari; Vladimir Hubka.

- Década de 1990: John Gero; Steven D. Eppinger e Karl T. Ulrich; Nigel Cross; Roozenburg e Eekels; Baxter.

- Século XXI: International Business Machines (IBM); Neves; Eder e Hosned; Brown; Handl.

Desses autores, os três primeiros citados em cada década serão utilizados para exemplificar os modelos metodológicos por eles desenvolvidos, de modo que seja possível a visualização do panorama metodológico em seus respectivos períodos. Já os dois últimos citados em cada década serão analisados a posteriori, para demonstrar o panorama metodológico, desde sua formalização (1960) até a contemporaneidade. 


\section{Décadas de 1960 e 1970}

Na década de 1960 começa a surgir a estruturação das metodologias de Design como as conhecemos hoje. Anteriormente a este período, os processos que guiavam o desenvolvimento de produtos não seguiam métodos claros e estruturados.

As metodologias deste período foram influenciadas pela pesquisa aeroespacial, uma vez que esta, apresentava problemas complexos a serem resolvidos e tinha como fundamento dividir o processo em passos discretos e bem definidos. (BURDEK, 2006).

Neste período, percebe-se que as metodologias, em sua maioria, são descritivas, não apresentando ainda o conceito de feedback entre fases - exceto pelo modelo de Archer. Os principais estudiosos eram engenheiros, desenvolvendo, assim, metodologias com um caráter mais matemático e lógico, buscando uma melhor descrição dos métodos e focando-se no processo de produção, não apresentando cuidados relacionados ao usuário ou pós-venda.

Já na década de 1970, foi iniciada uma nova abordagem na metodologia de Design, uma vez que surgia a necessidade de um método que privilegiasse a variedade de ideias. Bürdek (2006, p. 256-7) afirma que "para o conhecimento objetivo são necessárias muitas e diversas ideias. Para isso, é necessário um método que privilegie a variedade como único compatível com uma concepção humanística".

Neste período, os estudiosos deixam de ser, em sua maioria, engenheiros, dando espaço para autores de diversas áreas do conhecimento, que colaboravam com o desenvolvimento de metodologias. Isso acarretou em um processo com enfoques diversos, tais como, estudos ergonômicos, de custos e a preocupação com o usuário (JONES, 1992).

Bürdek (2006, p. 257) assinala que:

[...] até os anos setenta, os métodos empregados eram orientados na sua maioria dedutivamente, isto é, era desenvolvida para um problema geral uma solução especial (de fora para dentro). No novo design, trabalha-se de forma mais indutiva, isto significa se perguntar para quem (para que grupo específico) um projeto especial deva ser colocado no mercado (de dentro para fora). 
As metodologias deste período, em sua maior parte, tinham caráter prescritivo, estrutura mais linear de etapas, flexibilidade atemporal em suas etapas e feedbacks flexíveis entre elas.

Pode-se verificar a seguir um esquema das metodologias das décadas de 1960 e 1970:

Figura 2 - Esquemas metodológicos das décadas de 1960 e 1970

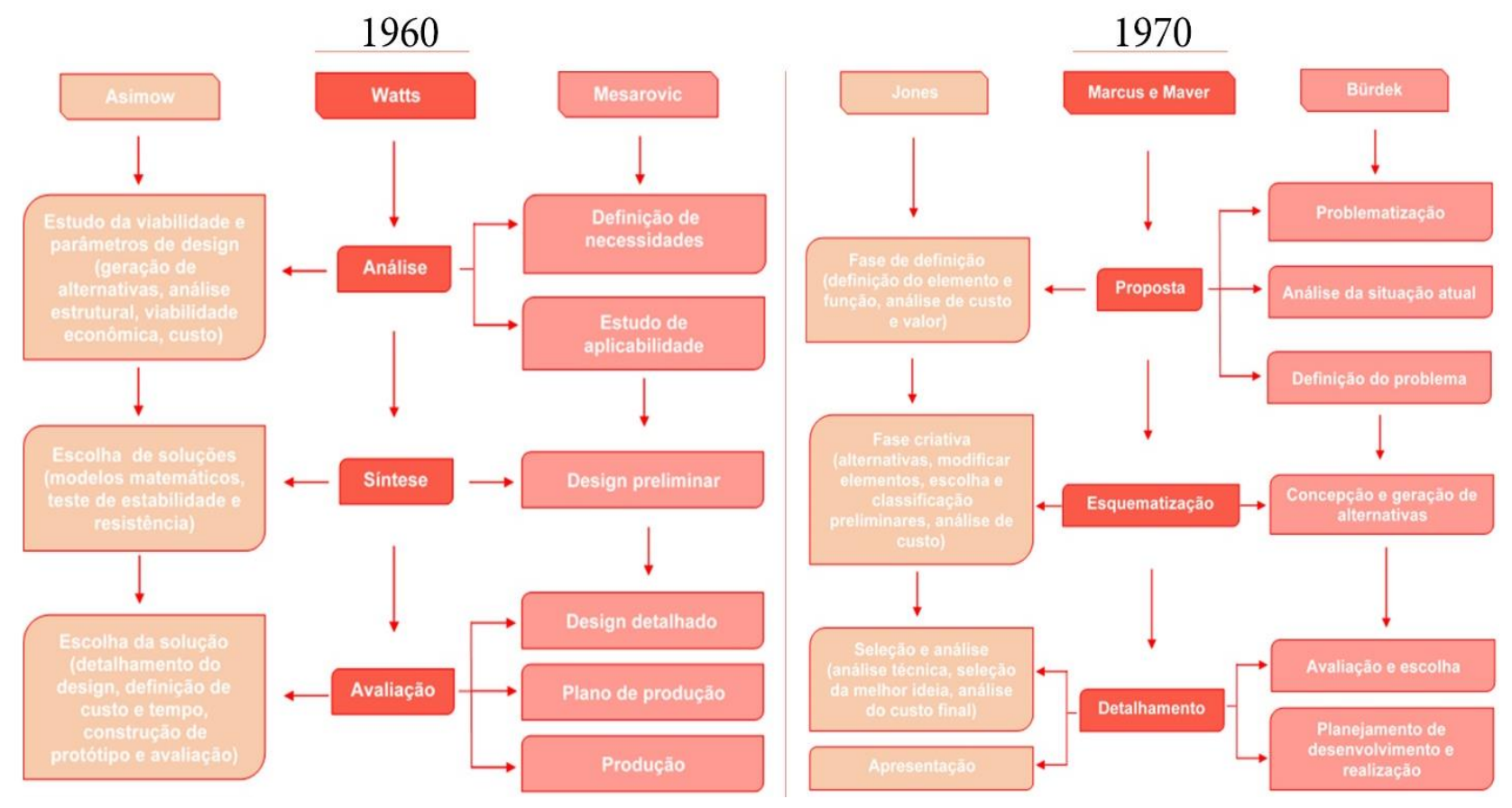

Fonte: Elaboração dos autores (2017).

\section{Décadas de 1980 e 1990}

$\mathrm{Na}$ década de 1980 a oposição ao modelo racional, matemático e determinístico ganhava mais força, podendo ser definida como um estado de transição entre correntes da metodologia de projeto. Bürdek (2006, p. 258) aponta que a "passagem das ciências naturais para as ciências humanas foi uma mudança de paradigma no design".

A estrutura linear das etapas e o caráter prescritivo permanecem nas metodologias, entretanto, percebe-se uma mudança relevante quanto à presença de feedbacks. Ao contrário do que aconteceu na década de setenta, os feedbacks entre fases eram quase inexistentes, mostrando uma redução da alta flexibilidade dos processos no período anterior. 
Já na década de 1990, a pós-produção, tal como o lançamento do produto no mercado, se tornava mais importante que o produto por si só. Bürdek (2006, p. 258) aponta que "nos anos 1990 se evidenciou a necessidade de novas orientações, determinadas pela cada vez mais frequente digitalização. "

O funcionalismo dava espaço para novos temas imateriais, tais como usabilidade e Design de interfaces. Esses fatores fortaleciam a necessidade de novos procedimentos metodológicos. (BÜRDEK, 2006). Nessa década, a metodologia possuía caráter essencialmente prescritivo, há o crescimento dos modelos de estrutura cíclica e os feedbacks estavam presentes.

Pode-se verificar a seguir um esquema das metodologias das décadas de 1980 e 1990:

Figura 3 - Esquema metodológico das décadas de 1980 e 1990

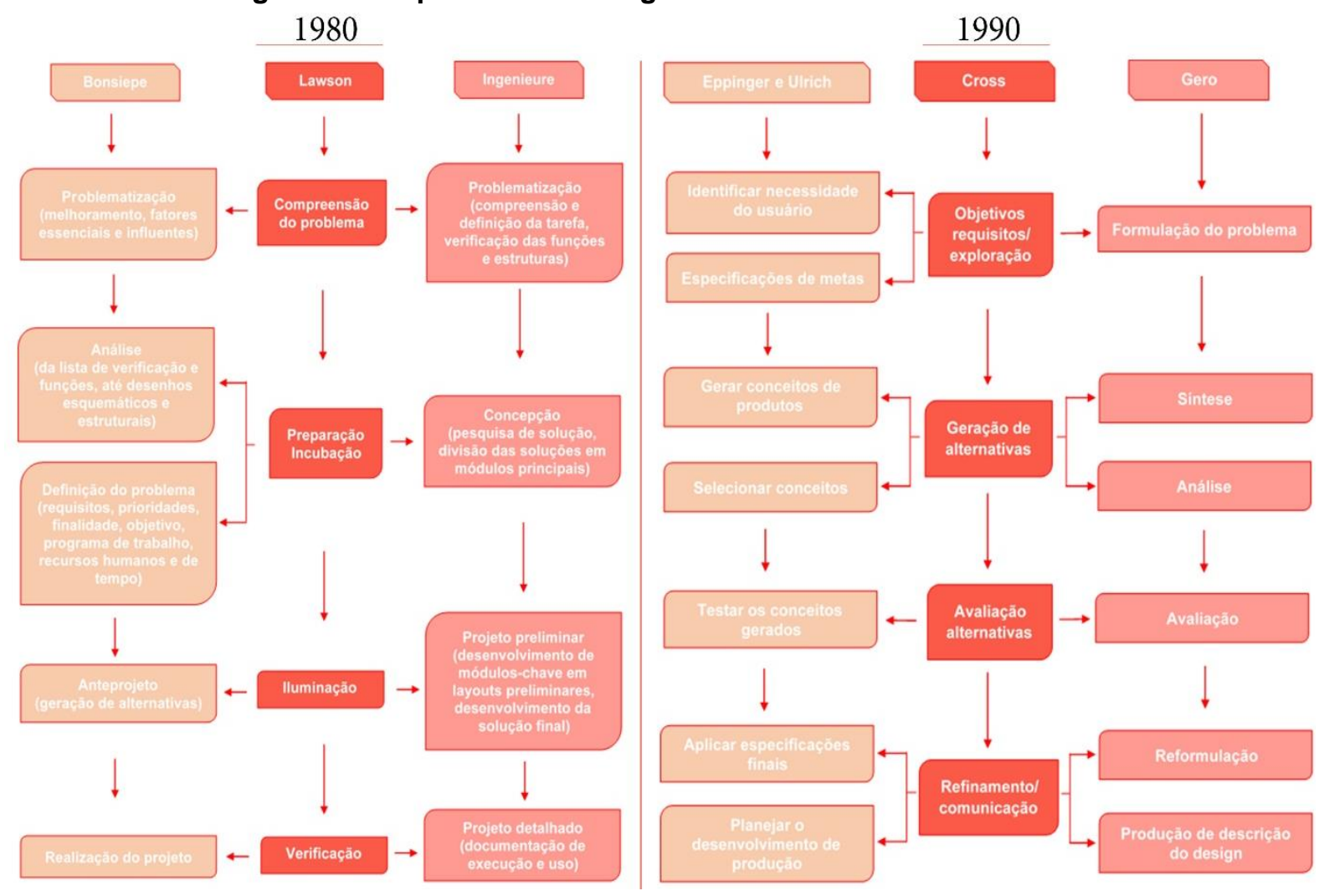

Fonte: Elaboração dos autores (2017). 


\section{Século XXI}

No século XXI o Design caminha em direção à multidisciplinariedade, com equipes formadas por especialistas das mais diversas áreas. As metodologias atualmente possuem um caráter flexível, ou seja, podem ser utilizadas como foram propostas ou adaptadas para as necessidades existentes nos projetos.

Na metodologia deste período, a prescrição dos métodos permanece como modelo dominante, porém, flexível e adaptável a diferentes situações. O processo de desenvolvimento de um produto é muito mais dinâmico e centrado no usuário, indo além do produto, pensando-se na experiência proporcionada.

Pode-se verificar a seguir um esquema da metodologia do Séc. XXI:

Figura 4 - Esquema metodológico do século XXI

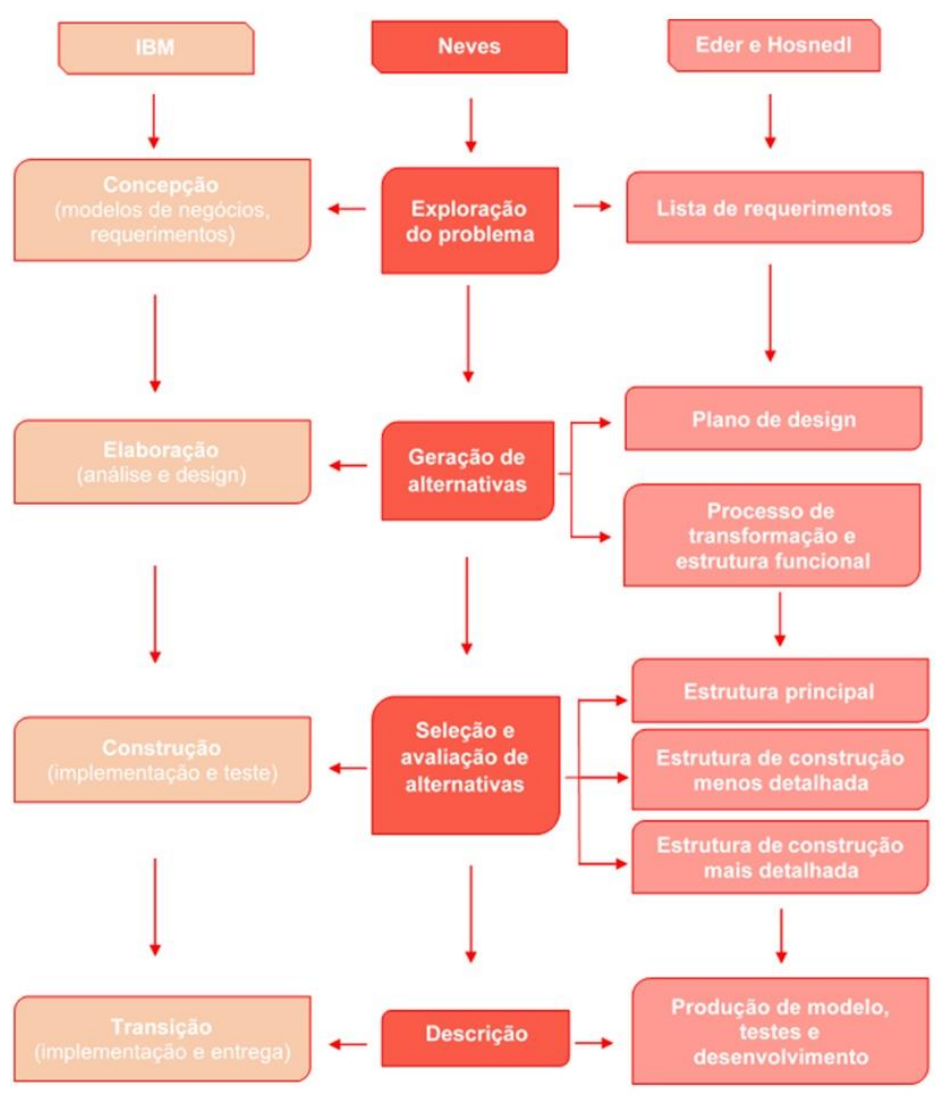

Fonte: Elaboração dos autores (2017).

As análises das metodologias do Design demonstram que, sejam clássicas ou contemporâneas, seguem um padrão linear nas análises e no desenvolvimento de 
projetos. As metodologias servem como diretrizes independentemente do projeto a ser criado e uma boa parte dos esforços do projeto são destinados à área de pesquisa. Segundo Munari (2011, p. 18): "O método projetual não é mais do que uma série de operações necessárias, dispostas por ordem lógica, ditada pela experiência. E o objetivo é o de se atingir o melhor resultado com o menor esforço."

Para demonstrar que as metodologias de Design, independente do período em que estão sendo utilizadas, mantêm sempre uma estrutura linear semelhante, partindo de algo complexo (problema) em busca de algo simples (produto final), elaborou-se o esquema abaixo, com dois dos principais autores de cada década.

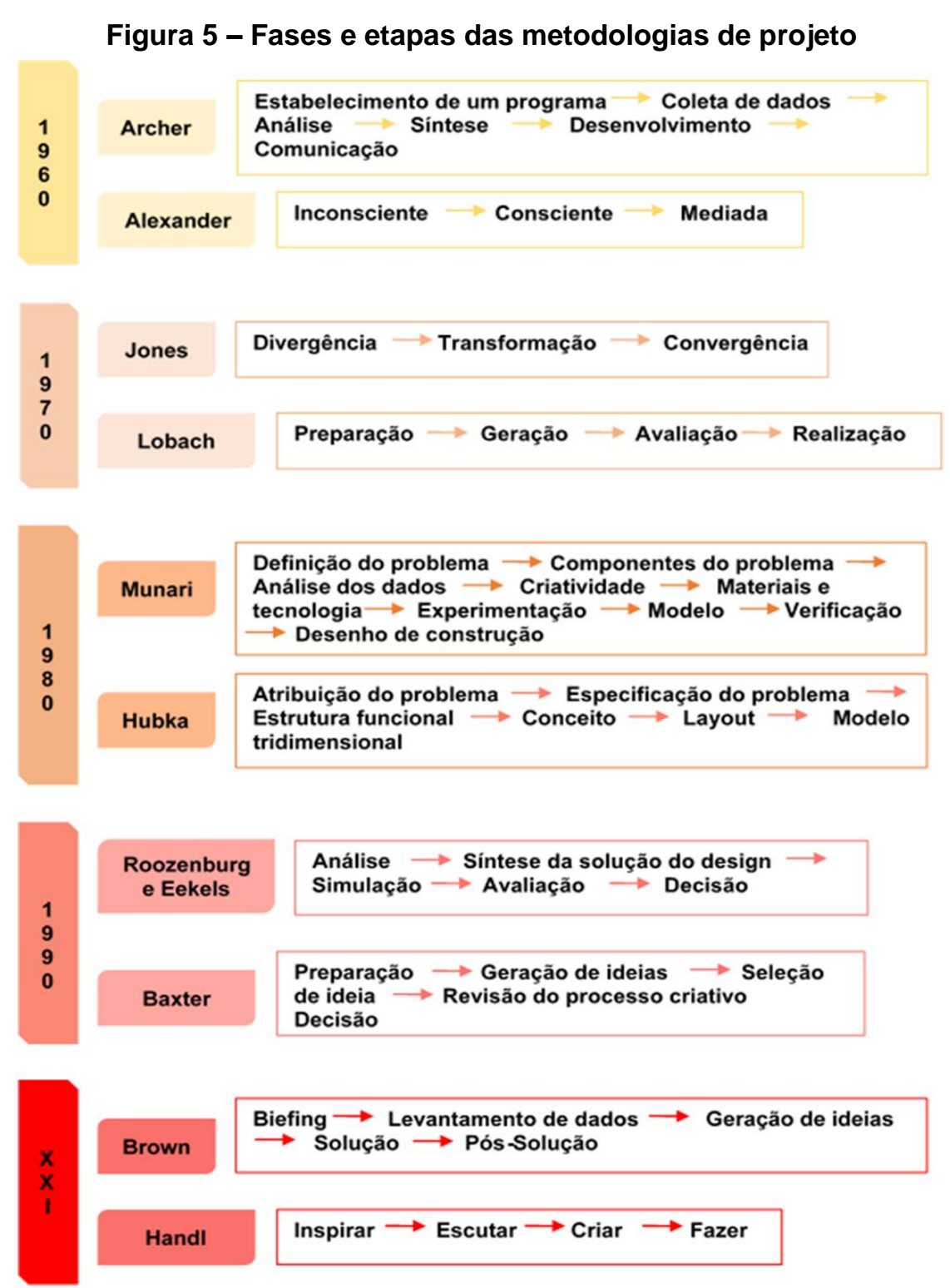

Fonte: Elaboração dos autores (2017). 
Constata-se então, que ao longo dos anos a estrutura das metodologias de Design, independente dos seus autores, não se modificou. Sempre se parte de um problema para chegar à solução. Neste sentido, elaborar uma nova abordagem de desenvolvimento de projeto, que siga um caminho diferente do habitual utilizado pelo Design, torna-se relevante, de forma que ela possa contribuir com o processo metodológico. Para isso, buscou-se referências em outro processo de desenvolvimento: a engenharia reversa.

\section{Engenharia reversa como referência para uma nova abordagem do Design}

Não há registro de quando se iniciou a utilização da engenharia reversa, entretanto, essa técnica era muito utilizada para se alcançar a soberania militar em guerras. Para que fosse possível alcançar independência e autonomia sobre decisões e processos de produção, utilizavam-se de espionagem e captura de um exemplar do armamento ou objeto que pretendiam recriar ou encontrar pontos fracos como vantagem sobre o inimigo.

A engenharia reversa foi e ainda é importante para a evolução da tecnologia e melhoramento de projetos, uma vez que é utilizada como modo de superar a defasagem de produtos concorrentes ou de própria autoria, o que estimula a evolução tecnológica desde o início da globalização.

A engenharia reversa é o estudo de um objeto existente, no qual sua estrutura é analisada peça por peça ao passo que é descontruído. Sendo assim, é possível constatar como ele foi fabricado; como é o seu funcionamento; como pode ser melhorado, a partir da análise de seus pontos fortes e fracos; quais peças devem ser eliminadas, mantidas ou melhoradas e quais as outras funções que o objeto de estudo poderia exercer.

A utilização da engenharia reversa diminui o tempo e o custo na etapa de pesquisa para a elaboração de um produto. Para Gonzalez Cardozo (2012, p. 21) "a engenharia reversa é uma tecnologia que permite criar produtos em prazos reduzidos, com ganhos de qualidade e custo. Seu conceito consiste em criar modelos virtuais a partir de um modelo existente". 
O método da engenharia reversa é muito utilizado na indústria, para que se possa manter a competitividade. Para Dias $(1996$, p. 1) "o atual processo de globalização torna crucial a obtenção e manutenção da competitividade de empresas e nações, enquanto acelera os processos de mudança tecnológica"

Portanto, a engenharia reversa é o método no qual se utiliza uma metodologia contrária a uma metodologia de desenvolvimento de produto tradicional, na qual um produto finalizado é desconstruído até chegar ao ponto de partida do projeto. Abaixo, segue um esquema simplificado da Engenharia Reversa:

$$
\begin{array}{r}
\text { Produto } \rightarrow \text { Desconstrução } \rightarrow \text { Análises das peças } \rightarrow \text { Melhoramento } \rightarrow \\
\text { Novo produto } \Leftrightarrow \text { Menor Custo/Maior Agilidade }
\end{array}
$$

A Engenharia reversa então é um processo que parte da solução de um produto, na busca de novas possíveis soluções. No Design isso também pode ser um caminho, uma vez que o uso do conceito da engenharia reversa pode contribuir com a melhoria na metodologia de projeto de Design, solucionando problemas mais rapidamente e eficientemente.

\section{Design Reverso}

O termo "reverso" foi tomado da engenharia para explicar uma possibilidade de abordagem que ainda não foi aventada no âmbito do Design, ou seja, uma oportunidade de análise reversa de produtos aplicada no Design.

Assim como foi mostrado até então, a Engenharia Reversa é utilizada na criação de produtos para que se mantenha a competitividade das grandes marcas. Entretanto, este método é utilizado principalmente na produção em massa e na pirataria. Surge então o questionamento: por que esta técnica seria importante na aplicação no Design?

Este método se encaixa muito bem na metodologia do Design, uma vez que possibilita diferentes formas de se enxergar um processo e melhorá-lo. A metodologia atual de Design segue um esquema linear. Porém segundo Munari (2011, p. 19) "o método projetual para o designer não é nada de absoluto nem definitivo; é algo que 
se pode modificar, se encontrarem outros valores objetivos que melhorem 0 processo".

A aplicação do Design reverso pode ser exemplificada nos seguintes contextos:

- Melhorar um produto a partir de sua análise funcional, na qual podem ser apontados melhoramentos ergonômicos no Design ou até mesmo modificações de peças para um melhor desempenho.

- Há também a possibilidade de redesign ou produtos totalmente inovadores inspirados em outros existentes, de uma forma rápida, eficaz e com gastos reduzidos.

- Este método pode auxiliar a adaptação de um produto a determinada situação, seja na utilização em conjunto com outros produtos ou para usuários que necessitam de um Design exclusivo para uma melhor utilização.

Estes são só alguns exemplos da sua utilização. O processo de análise reversa aplicada no Design pode ser uma forma de otimizar gastos, tempo e adequar os produtos para os usuários. O Design reverso é, portanto, uma abordagem diferenciada e inovadora, que possibilitará possíveis novas soluções de uma forma mais ágil e direta. De uma forma simplificada, o Design reverso segue a seguinte estrutura:

Figura 6 - Estrutura básica do Design Reverso

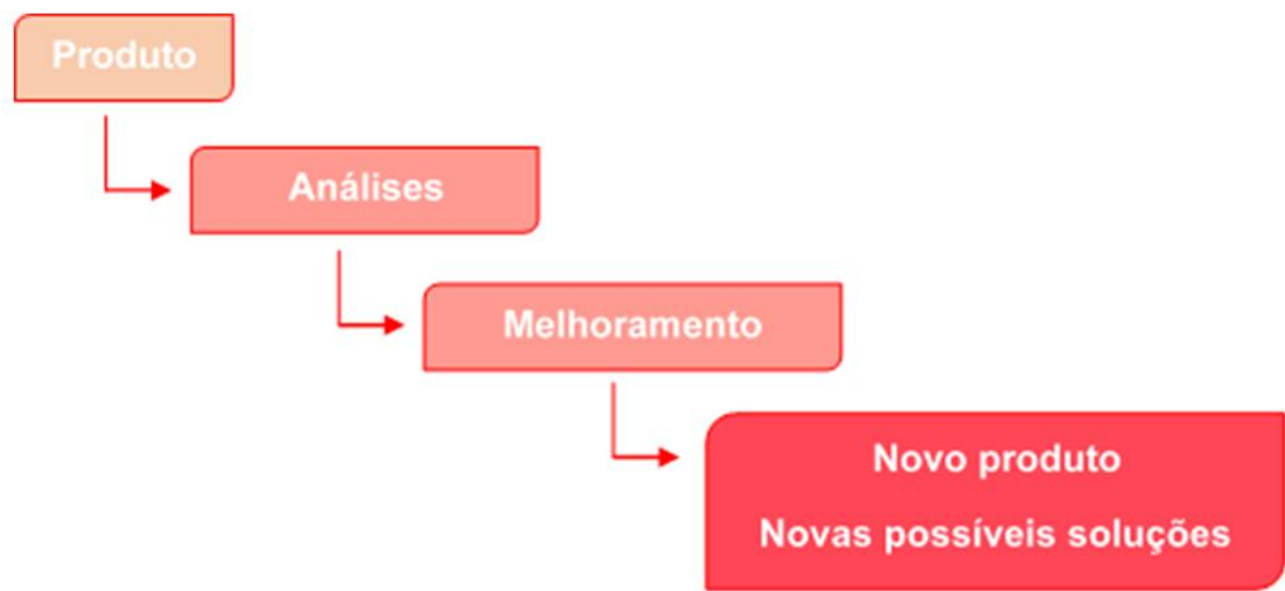

Fonte: Elaboração dos autores (2017).

Esta abordagem permitirá analisar o produto esteticamente e funcionalmente, levando-se em consideração a interação com o usuário. Após essa etapa seria 
analisada as peças que compõem o produto ao longo da sua desconstrução, observando-se possibilidades de acrescentar, eliminar ou otimizar peças. Após essas etapas ocorreria os melhoramentos na análise crítica do produto, observando possíveis melhorias nas estruturas do objeto, seja ergonomicamente ou estruturalmente, ou até mesmo de alguma peça específica. Já a fase final dependeria da situação apresentada, a criação de algo novo inspirado em algum conceito do produto original ou a criação de uma peça para fazer algo totalmente diferente ou, ainda, uma nova solução para o produto original.

\section{Design reverso: um modelo de abordagem}

De forma a estruturar o que foi apresentado no capítulo anterior, desenvolveuse um modelo visual da abordagem do Design reverso, que consiste em duas análises: sendo a primeira genérica, na qual o indivíduo poderá responder livremente com base em seus conhecimentos, e a segunda análise será estruturada, onde o indivíduo será conduzido a desenvolver uma análise reversa com base em etapas estruturadas e sequenciais. Os dados coletados destas análises proporcionarão o melhoramento do produto analisado ou o desenvolvimento de um novo produto, como pode-se verificar a seguir: 
Figura 7 - Design Reverso: modelo de abordagem

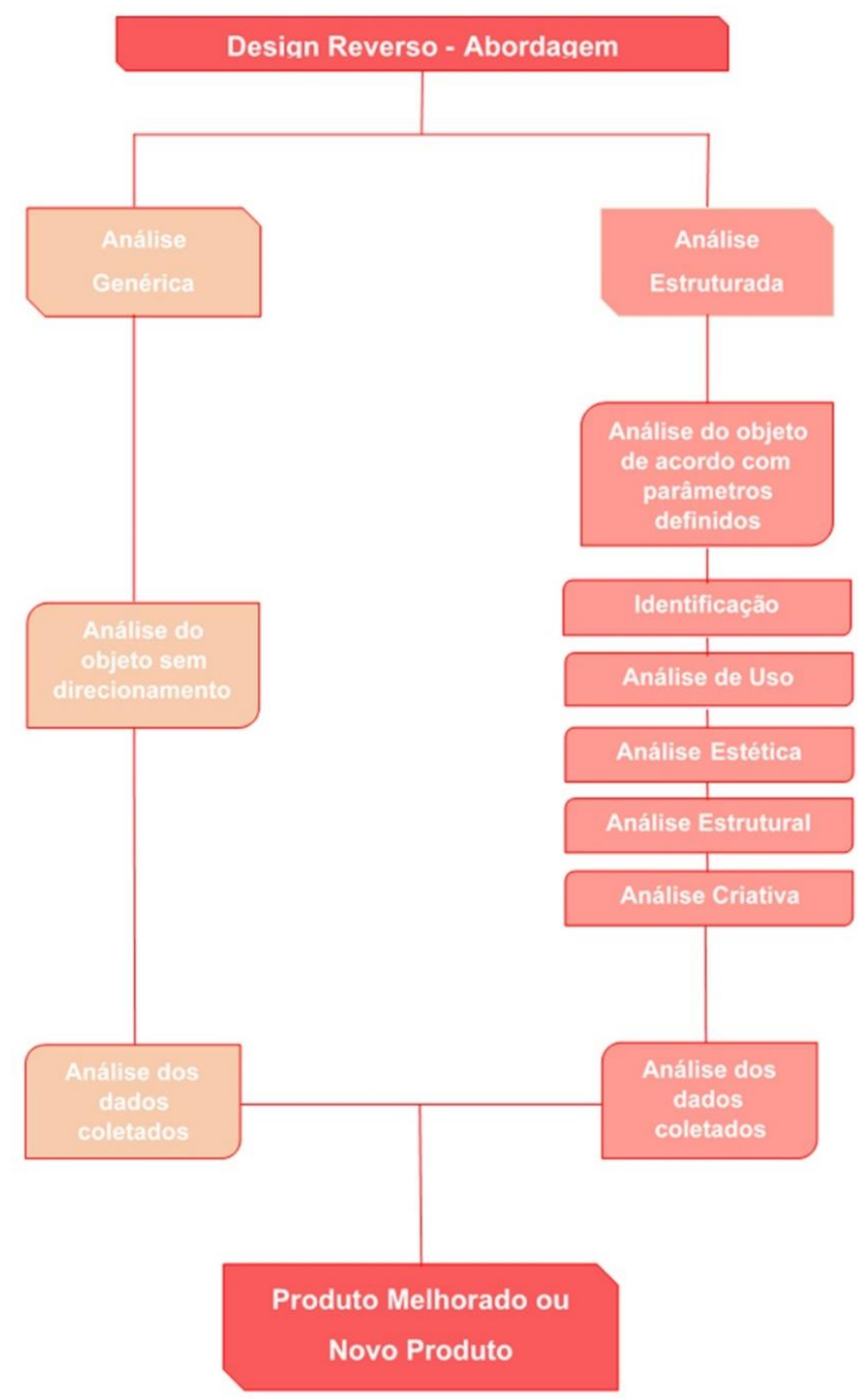

Fonte: Elaboração dos autores (2017).

\section{Considerações Finais}

Neste artigo buscou-se evidenciar que os processos metodológicos de Design passaram por pequenas alterações ao longo das décadas, entretanto essas não mudaram sua estrutura básica de desenvolvimento de produto, partindo sempre de um problema (algo complexo), buscando uma solução (algo simples).

Deste modo, com o intuído de ampliar as possibilidades de opções e formas de desenvolvimento de produtos, apresenta-se o Design Reverso, que consiste em uma nova abordagem de desenvolvimento de produtos, na qual as análises partem de um artefato já existente (algo simples). Como demostrado, é composta por duas etapas: 
uma generalista e outra estruturada. A partir destas suas análises são realizadas, obtendo-se como resultado um produto melhorado ou um novo produto.

Essa abordagem ainda se encontra em fase de desenvolvimento, de forma que este artigo tem como função apenas apresentar seu escopo inicial. O Design reverso não possui a pretensão de ser ou se tornar uma nova metodologia, mas sim uma nova ferramenta, que pode contribuir ou complementar as metodologias vigentes. Seu principal objetivo é colaborar com os docentes e acadêmicos de Design, permitindoIhes entrar em contato com uma nova forma de desenvolvimento de produtos.

\section{Referências}

BÜRDEK. Bernhard E. História, teoria e prática do design de produtos. Trad. Freddy Van Camp. São Paulo: Edgard Blücher, 2006.

GONZALEZ CARDOZO, Carlos Aurelio. Manufatura digital aplicada no contexto de engenharia reversa: estudo de caso: protótipo virtual do avião Blériot. 2012. 105 p. Dissertação (Mestrado) - Universidade Estadual de Campinas, Faculdade de Engenharia Mecânica, Campinas, SP, 2012.

DIAS, Adriano Batista. Engenharia reversa: uma porta ainda aberta. Recife: FUNDAJ, 1996.

GROPIUS, Walter. Bauhaus: novarquitetura. São Paulo: Ed. Perspectiva, 2004.

JONES, John Christopher. Design methods: seeds of human futures. 2. ed. London: John Wiley \& Sons Ltd., 1992.

MARTINS, Roseane F. de Freitas; VAN DER LINDEN, Júlio Carlos de Souza (Org.). Pelos caminhos do design: metodologia de projeto. Londrina: Eduel, 2012.

MUNARI, Bruno. Cómo nacen los objetos?: apuntes para una metodologia proyectual. Barcelona: Ed. Gustavo Gili, 2011.

NIEMEYER, Lucy. Design no Brasil: origens e instalação. Rio de Janeiro: 2AB, 2000.

VASCONCELOS, Luis Arthur Leite de. Uma investigação em metodologias de design. 2009. $94 \mathrm{f}$. Projeto de Conclusão do Curso (Curso de Design) - Departamento de Design, Universidade Federal de Pernambuco, Recife, 2009.

VELA, João Carlos. Design de produto: as concepções de formação pela perspectiva de seus docentes. São Paulo: Ed. Blucher, 2010. 


\section{João Carlos Vela}

Professor Adjunto dos cursos de Design e Arquitetura da Universidade da Região de Joinville, especialista em ensino da expressão gráfica - UFPR, mestre em educação pela FURB, aluno do programa de doutorado do Pós-Design UFSC.

E-mail: joao.vela1@gmail.com

Currículo: http://lattes.cnpq.br/5401945859116505

\section{Ricardo Triska}

Doutor em Engenharia da Produção, Professor associado, lotado no departamento de Expressão Gráfica-UFSC. Docente do Programa de Pós-graduação em Design e Expressão Gráfica, Coordenador da Área de Arquitetura, Urbanismo e Design junto à CAPES.

E-mail: ricardo.triska@gmail.com

Currículo: http://lattes.cnpq.br/4367773030316525

\section{Beatriz Andrielly de Souza Nascimento}

Graduanda do curso de Design de Interiores da Universidade da Região de Joinville, participante do grupo de pesquisa: Núcleo de Pesquisa em Design de Interiores.

E-mail: bia28andry@gmail.com

Currículo: http://lattes.cnpq.br/9153384495561463

Recebido em 14 de julho de 2017 Aceito em 25 de novembro de 2017 